\title{
Steroid histochemical study of the adrenal gland of adult Sudanese chicken (Gallus domesticus) and duck (Anas platyrhynchos)
}

\begin{abstract}
${ }^{1}$ Dr. Salwa Ismail Abdelgader Elbajory ${ }^{*},{ }^{2}$ Dr. Muddthur D. El Tingari and ${ }^{3} \mathrm{Dr}$. Mohamed Ahmed Abdalla ${ }^{1}$ Faculty of medical laboratory science,Omdurman Islamic university,Sudan.

${ }^{2} 3$ Faculty of Veterinary science, Khartoum university,Sudan.
\end{abstract}

\section{Abstract:-}

In Sudan (Khartoum state), the material was collected during the winter and summer seasons .The aim of the work to show the steroid histochemical of the adrenal gland of adult Sudanese chicken (Gallus domesticus) and duck (Anas platyrhynchos).The adrenal glands were two small organs, irregularly oval and pale yellow in the colour (Ghosh et.al.2001 and Sarker et.al.2014).The histochemical localization of steroid enzymes was studied in the adrenal gland of adult chicken and duck. $\Delta^{5}-3 \beta$ hydroxysteroid dehydrogenase and 17 $\beta$-hydroxysteroid dehydrogenase were demonstrated solely in the cortex. 


$$
\begin{aligned}
& \text { مستخلص البحث:- } \\
& \text { من ناحية عياتية تتميز الغدة الكظرية في الديوك وذكور البط بلوها الأصفر الفاتح غير }
\end{aligned}
$$

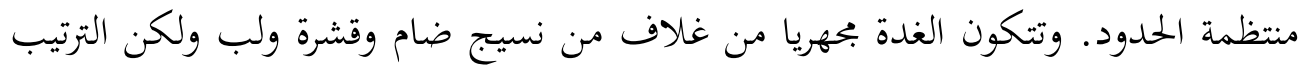

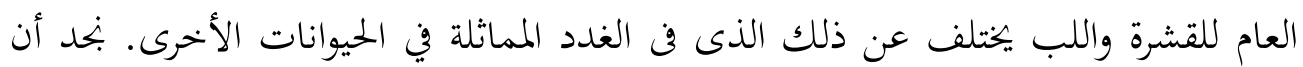

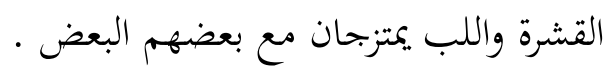

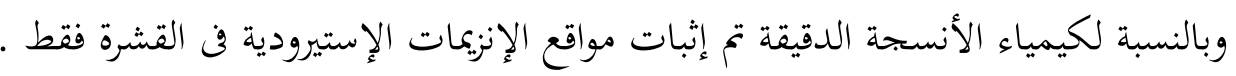

\section{Introduction}

The localization of some steroid enzymes in the adrenal cortex was undertaken by Baillie et.al.(1966), Zeqiri, Rozhaja and hullinger(1985), Blanchi, Piezzi, Seltzer and Souto(1986), and Tetzlaff (1987). In the present study, it as decided to examine the adrenal cortex of fowl and duck for the localization of $\Delta^{5}-3 \beta \_$hydroxysteroid dehydrogenase, an enzyme which is present in all steroid hormone producing tissues and 17 $\beta$-hydroxysteroid dehydrogenase, which catalyses most of the interconversions in steroid metabolism and to establish if there are seasonal variations.

Search in the literature has shown no steroid histochemical data on adrenal gland of any of the avian species in Sudan. The aim of the work to show the steroid histochemical of the adrenal gland of adult Sudanese chicken (Gallus domesticus) and duck (Anas platyrhynchos) .

The aim of the work to show the steroid histochemical of the adrenal gland of adult Sudanese chicken (Gallus domesticus) and duck (Anas platyrhynchos) . 


\section{Materials and Methods}

In Sudan (Khartoum state), the material was collected during the winter and summer seasons from twelve mature male Hisex brown chickens and twelve mature male ducks. The birds were killed by dislocation of the neck vertebrae and samples of tissues were obtained from the adrenal gland.Tissues were immediately fresh - frozen in liquid nitrogen and cut at a thickness of $16 \mu \mathrm{m}$ in a crystat maintained at $-20^{\circ} \mathrm{c}$. Sections were attached to cover slips, allowed to dry by momentry thawing, covered with the incubating medium and transferred to a moist chamber at $37^{\circ} \mathrm{c}$ for 1 to 2 hours.

The incubating medium was essentially the same as that obtained by Baillie et.al. (1966). $\mathrm{NAD}^{+}$was used as co-factor and nitro BT as the electron accepter. $3 \beta-$ hydroxyandrost-5-en-17one (DHA) and $3 \beta$ hydroxypregn-5-en-20one (pregnenolone) were used as substrate for detecting $\Delta^{\mathbf{5}}$-hydroxysteroid dehydrogenase. Control sections were incubated in the medium lacking the substrate.

Following incubation, the sections were washed in buffer, rinsed in water, fixed for 10 minutes in $10 \%$ formalin, thoroughly washed and mounted in glycerine jelly. 


\section{Results \\ Gross feature of the adrenal gland of adult chicken and duck :-}

These were two small organs situated close together medial to the anterior lobes of the kidney in the neighbour-hood of the testis and caudal to lungs (Fig.1,2). The glands were flattened and irregular in out line, pale yellow in the colour. Adipose connective tissue adhered to the adrenal surface of the gland.

\section{Fig.1:-}

The adrenal gland of the domestic fowl. $\mathrm{R}$, right adrenal . L, left adrenal.

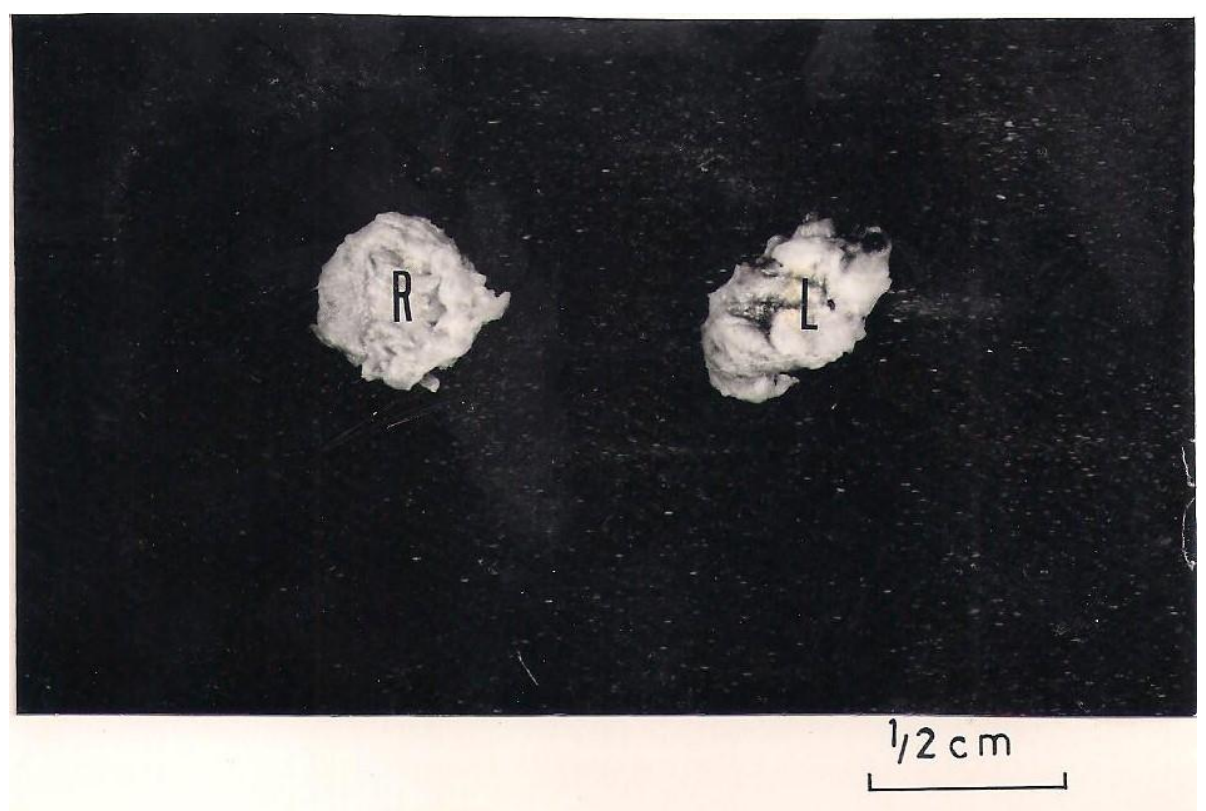




\section{Fig.2:-}

The adrenal gland of the duck. $\mathrm{R}$, right adrenal . L, left adrenal.

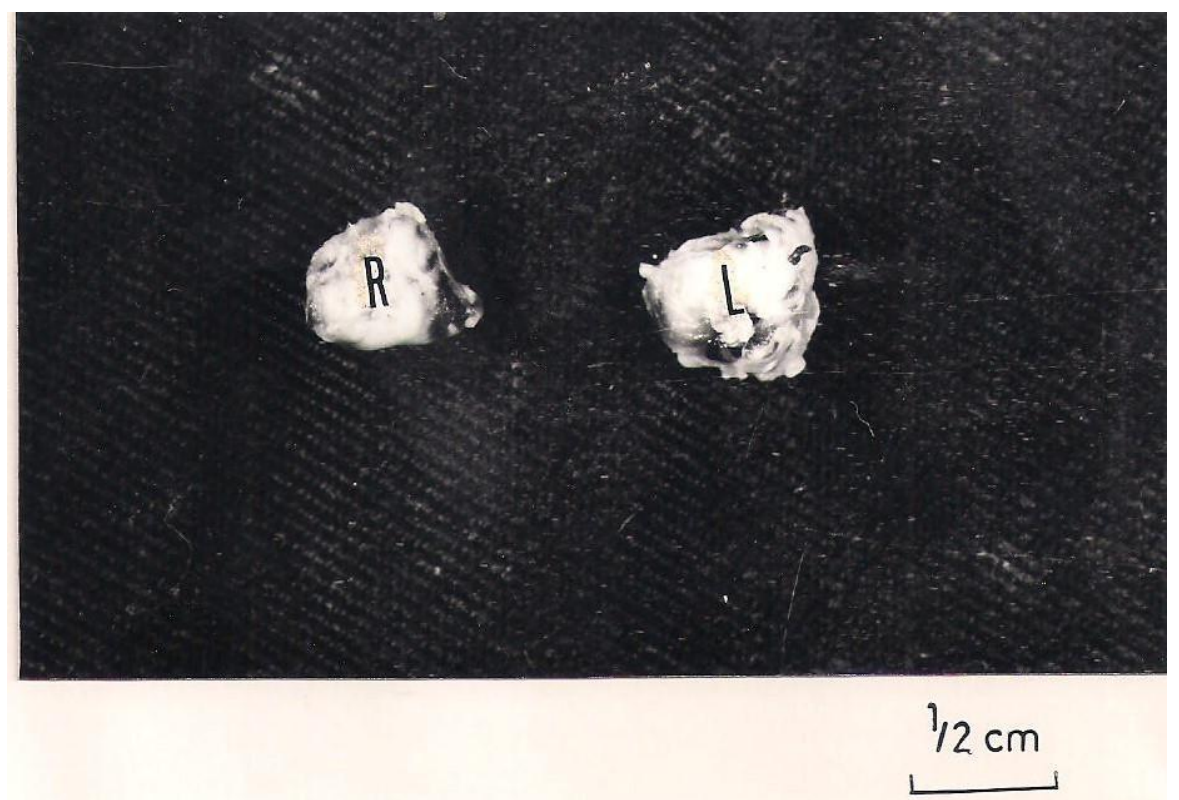

Steroid histochemical observations of the adrenal of adult chicken:-

The result of all material investigated were summarized in table 1.The observation included the cortex as the medulla was unreactive. The staining reaction obtained was essentially the same for both summer and winter material utilized. All control section showed a very weak staining reaction. 


\section{Table 1:}

Summary of material investigated histochemically in the adrenal gland of adult Hisex brown chicken (summer and winter season)

\begin{tabular}{|c|c|c|c|}
\hline Tissue & DNA & pregnenolone & testosterone \\
\hline cortex & +++ & +++ & + \\
\hline medulla & - & - & - \\
\hline
\end{tabular}

$++=$ strong $\quad+=$ weak $\quad-=$

negative

\section{$\underline{\Delta^{5}-3 \beta \text { hydroxysteroid dehydrogenase }}$}

Both DHA and pregnenoline gave the same pattern of distribution of the reaction when used as substrates. Positive formation granules were seen in the cortex only (Fig3,4).

\section{Fig.3:-}

Fowl adrenal . $\Delta^{5}-3 \beta$ hydroxysteroid dehydrogenase, substrate DHA. Incubated with $\mathrm{NAD}^{+}$. 100X.

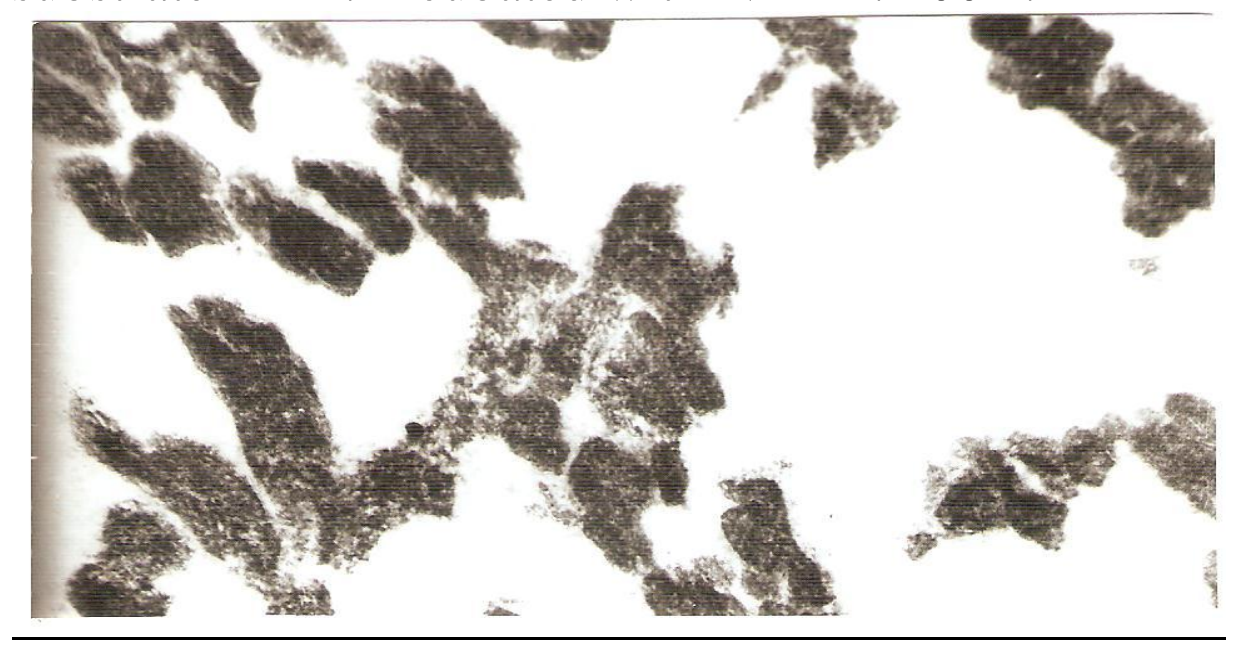




\section{Fig.4:-}

Fowl adrenal $. \Delta^{5}-3 \beta$ hydroxysteroid dehydrogenase, substrate pregnenolone. Incubated with NAD+. $100 \mathrm{X}$.

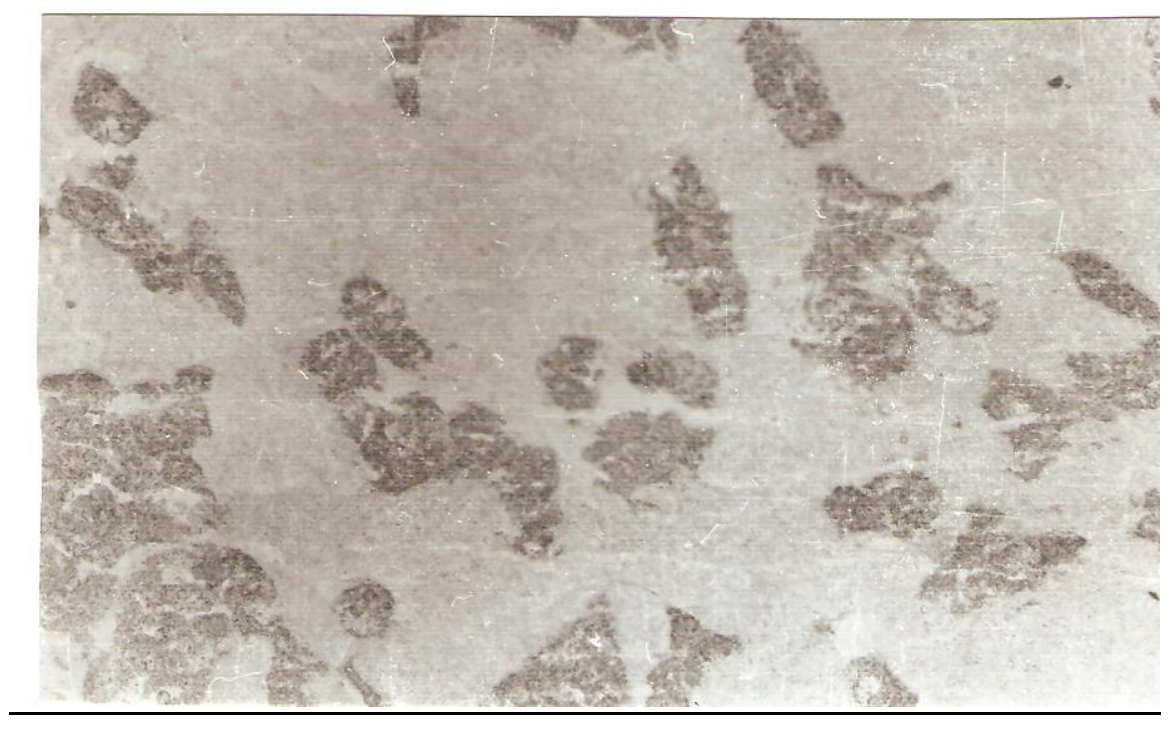

17ß-hydroxysteroid dehydrogenase

Testosterone gave the same pattern of distribution of the reaction as revealed by DHA and pregnenolone when used as substrates. Positive formazan granules were seen in the cortex ( Fig.5).

\section{Fig.5:-}

Fowl adrenal. $\Delta^{5}-3 \beta$ hydroxysteroid dehydrogenase, substrate testosterone. Incubated with $\mathrm{NAD}^{+} .100 \mathrm{X}$. 


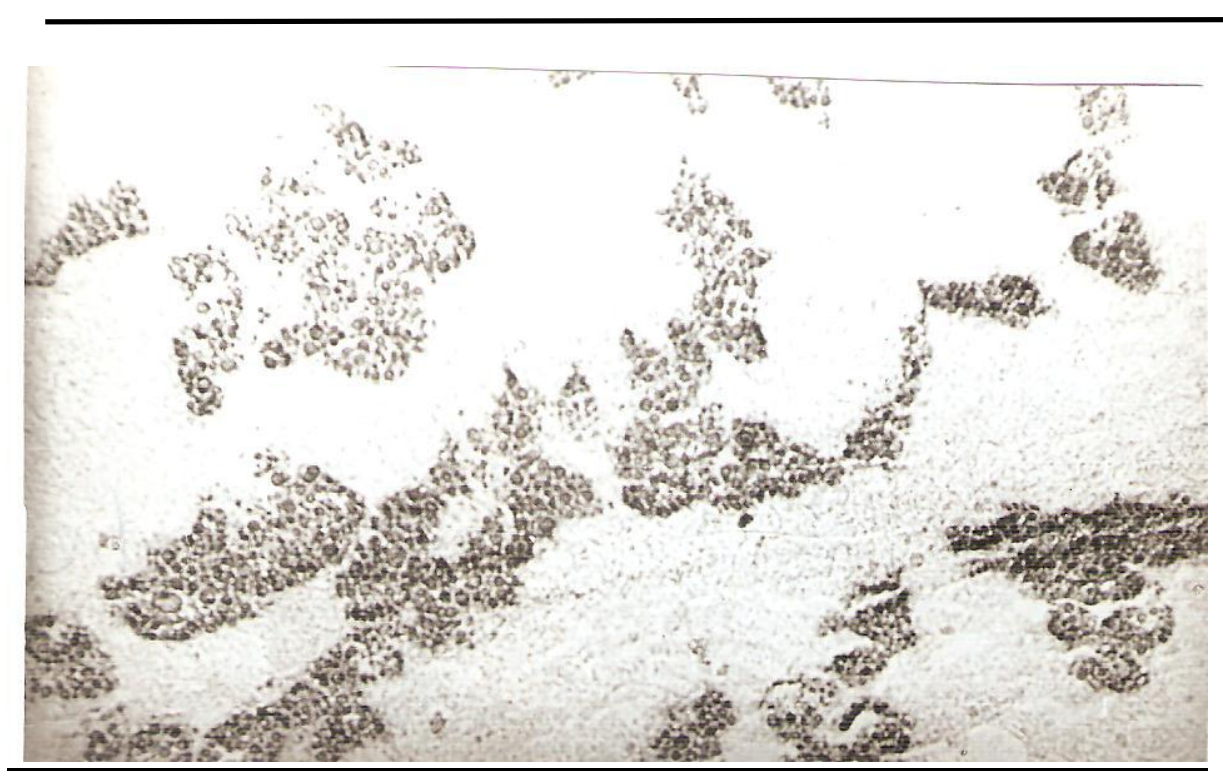

\section{Steroid histochemical observations of the adrenal of adult duck:-}

The summarization in table 2 included the result of all material investigated. A positive reaction was seen in cortex only for both summer and winter material utilized. All control sections showed a very weak staining reaction, this is due to what is explained above.

\section{Table 2 :-}

Summary of material investigated histochemic in the adrenal gland of adult duck (summer and winter season)

\begin{tabular}{l}
\begin{tabular}{|c|c|c|c|l|}
\hline Tissue & DNA & pregnenolone & testosterone & \\
\hline Cortex & +++ & +++ & + & \\
\hline medulla & - & - & - & \\
\hline
\end{tabular}$+++$ strong \\
\hline
\end{tabular}




\section{$\underline{\Delta^{5}-3 \beta}$ hydroxysteroid dehydrogenase}

In the cortex, positive formazan were seen with the same pattern of distribution of the reaction when both DHA and pregnenolone used as substrates (Fig.6,7).

\section{Fig.6:-}

$\Delta^{5}-3 \beta$ hydroxysteroid dehydrogenase, In Duck adrenal substrate DHA. Incubated with $\mathrm{NAD}^{+} .100 \mathrm{X}$.

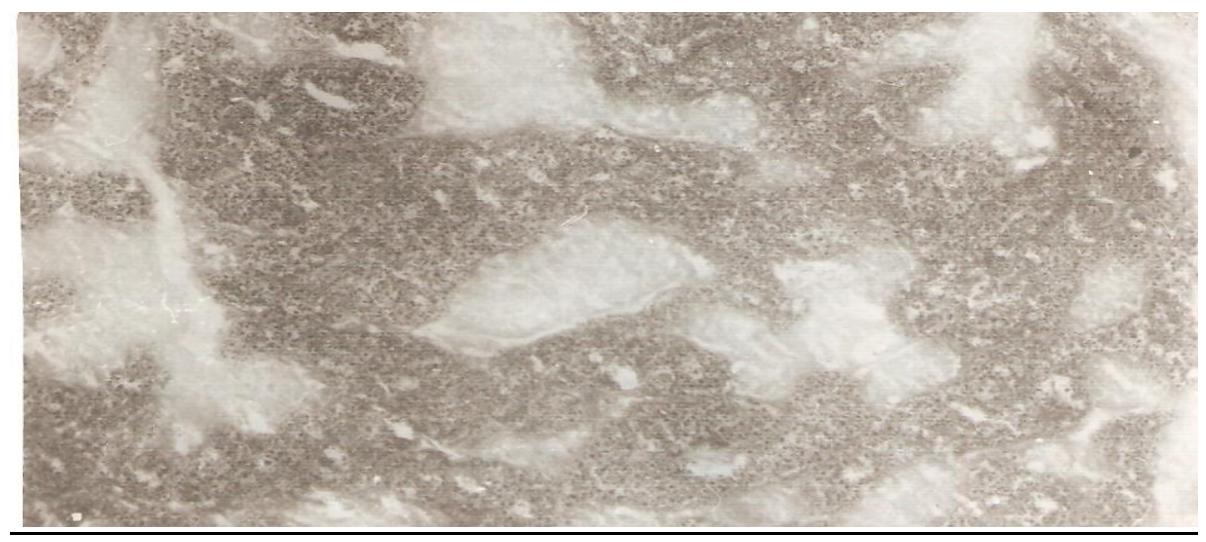

\section{Fig.7:-}

$\Delta^{5}-3 \beta$ hydroxysteroid dehydrogenase, In Duck adrenal substrate pregnenolone. Incubated with $\mathrm{NAD}^{+} .100 \mathrm{X}$.

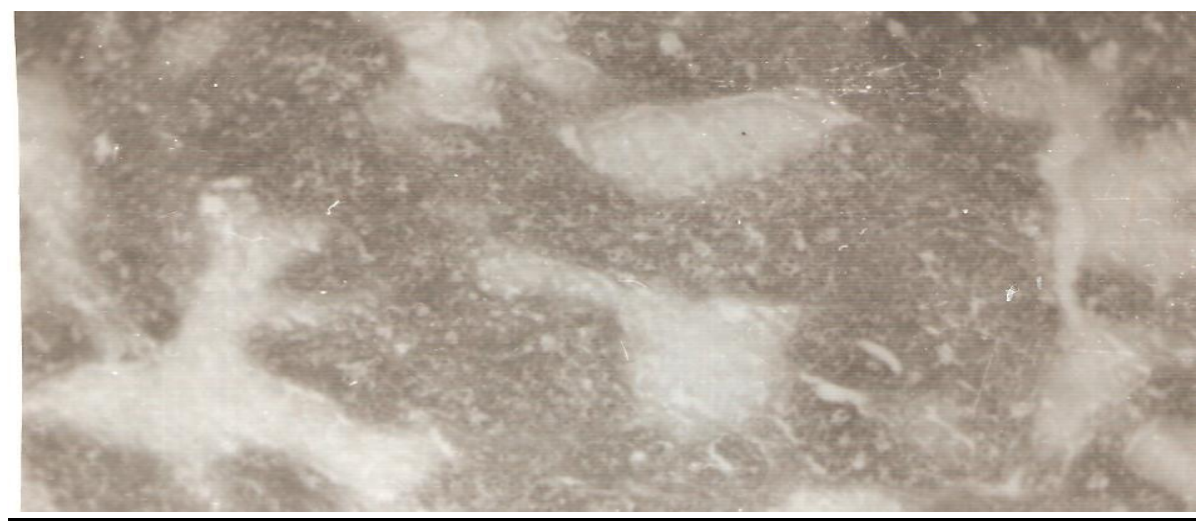




\section{7ß-hydroxysteroid dehydrogenase}

Positive formazan granules were seen in the cortex. The same pattern of distribution of the reaction as revealed by DHA and pregnenolone was also given by testosterone when used as the substrate (Fig.8).

\section{Fig.8:-}

$\Delta^{5}-3 \beta$ hydroxysteroid dehydrogenase, In Duck adrenal substrate testosterone. Incubated with $\mathrm{NAD}^{+} .100 \mathrm{X}$.

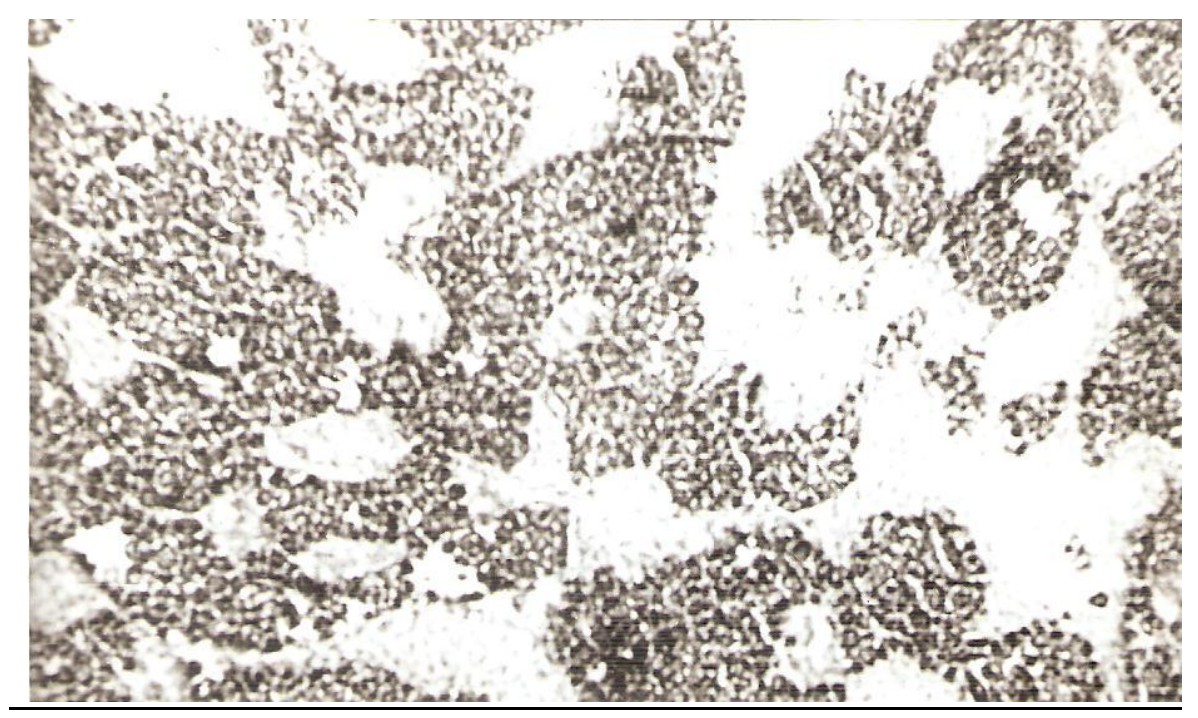

\section{Discussion}

$\Delta^{\mathbf{5}}-3 \beta$ hydroxysteroid dehydrogenase was localized in the cortex of adult chicken and duck with the same pattern of distribution. This enzyme could be demonstrated in all normal adrenal cortex . Baillie et.al. (1966) reported the presence of the enzyme in the cortex of rat, rabbit, mouse, monkey, dog, guinea-pig, ox, chicken, hamster but particularly remarkable in the 
human adrenal. Histochemical localization of $\Delta^{5}-3 \beta$ hydroxysteroid dehydrogenase has been Demonstrated in the adrenocortical tissue of Stainnus of Pseudopleuronecten americonus by Bara (1972).

Positive reaction due to 17 $\beta$-hydroxysteroid dehydrogenase in adrenal gland utilized in this study has been weak in both summer and winter seasons. Pearson and Grose (1959 a,b) and Fuhrmann (1961) failed to demonstrate $17 \beta$-hydroxysteroid dehydrogenase in rodent adrenal cortex. Also Zeqiri et.al. (1985) was unable to demonstrate enzyme in water - buffalo, but levy et.al. (1959) obtained an NAD linked colour reaction with testosterone as substrate in all zones of the rat adrenal gland.

Hart et.al. (1966) noted trace activity in the zona fasciculate of mouse adrenal glands at the approach of maturity. Calman et.al. (1966) recorted weak 17ßhydroxysteroid dehydrogenase in human foetal and adult adrenal gland.

In the adult adrenal gland weakly activity was confined to the outer part of the zone fasciculate and the zona reticularis. The frog adrenal exhibts weak 17ßhydroxysteroid dehydrogenase activity.

The finding and interpretation reported in this study provide basic information and indicates that further investigation involving ultra - structure and immunohistochemistry would contribute to a better understanding of these organs and correlates structure and function of the testes and adrenal glands. 


\section{References}

Ghosh. A., Carmichael, S. W. and Mukherjee.(2001). Avian adrenal medulla: cytomrphology and function. Acta Biologica Szegediensis Acta Biol Szeged . 45 (45) : $1-41$.

Baillie , A.H.; Ferguson, M.M. and Hart, D.M.(1966) . Development in steroid histochemistry. London and New York ; Academic press.

Blanchi, R.A.; Piezzi,R.S.; Seltzer, A. and Souto, M. (1986). Histochemical demonstration of $\Delta^{\mathbf{5}}-3 \beta$ hydroxysteroid dehydrogenase and plasma corticosterone in the neonatal adrenal cortex. Community biology . 5, 39-50.

Bara, G. (1972). Histochemistry of hydroxysteroid dehydrogenases in the testis, adrenocortical tissue and corpuscles of stainnus of pseudo-pleuronectes americonus. Acta Histochemica. 44,333 - 347.

Calman,K.C.; Baillie,A ferguson,M.M. and Hart,D.M. (1966). Hydroxysteroid dehydrogenases in the human adrenal cortex. Journal of endocrinology. $34,439-446$.

Fuhrmann,K. (1961). Uber den histochemischem Nachweis der $3 \beta$

-oI-steroid dehydrogenase-aktivitat in geweben endokrins organe. Zentralbiatt. Gynaekol. 15,565 572.

Hart,D.M.; Baillie,A.H.; Galman,K.C. and Ferguson,M.M. (1966). Hydroxysteroid dehydrogenase 
development in mouse adrenal and gonads. Journal of anatomy. 34,439- 446.

levy, H.; deane, H.W. and Rubin,B.L. (1959). Visulazation of steroid $3 \beta$-oI-steroid dehydrogenase activity in tissues of intact and hypophysectomized rat. Endocrinology . 65,932-943.

Pearson, B. and Grose, P. (1959 a) . Histochemical demonstration of 17 $\beta$-hydroxysteroid dehydrogenase by use of tetrazolium salt . Proceeding of the society of experimental biology and medicine . 100, 636-638.

Pearson, B. and Grose, P. (1959 b) . Histochemical study of some DPNH and DPN dependant dehydrogenasis . Federation Proceeding. 18, 499.

Sonjoy Saker,S; 1slam, M.N.; Adhikery, G. N.; Paul,B. and Bhowmik, N. (2014). Morphological and histological studies on the adrenl gland in male and female chicken (Gallus domesticus). International Journal of Biological and Pharmaceutical research . 5(9) : $715-718$.

Tetzlaff, G. (1987). 3ß-oI-steroid dehydrogenase in testis and epiphysis of Pekin drake Anas platyrhnchos .Acta Histochem. 81, $19-34$.

Zeqiri, F.R.; Rozhaja, D.R. and hullinger, R.L. (1985) . Histochemical identification of some hydroxysteroid dehydrogenase in adrenal cortex of water buffalo eperimentalis. 10, $41-46$. 